\title{
UN MOMENTO: HIBRIDEZ DE ÉPOCAS
}

APUNTES SOBRE ALGUNOS COMPONENTES DEL REALISMO MÁGICO

\author{
Ádám András Kürthy \\ Universidad Eötvös Loránd \\ kurthy.adam.a@gmail.com
}

Resumen: El objetivo de este artículo es reflexionar brevemente sobre algunos puntos de las declaraciones de Alejo Carpentier y de Gabriel García Márquez en cuanto a los conceptos de "lo real maravilloso" y del "realismo mágico", para continuar aduciendo algunos componentes históricos que han contribuido de manera menos advertida a la formación de este ideario, y terminar viendo sus huellas textuales en un relato de García Márquez, acabando en alguna conclusión acerca de la productividad de una expresión de uso tan variada y tan confusa como la del "realismo mágico".

Palabras clave: realismo mágico, real maravilloso, Gabriel García Márquez, Alejo Carpentier, "Blacamán el bueno, vendedor de milagros"

\begin{abstract}
The purpose of this article is to offer a short reflection on some statements made by Alejo Carpentier and Gabriel García Márquez about the concept of "the marvelous real" and "magical realism", going on afterwards to cite some historical elements that have contributed in a less noticed way to shaping this ideology, and to show its textual marks in one of García Márquez's short stories, and getting, in the end, to some conclusion about the productivity of the expression "magical realism", so varied and blurry in its use.
\end{abstract}

Keywords: magical realism, marvellous real, Gabriel García Márquez, Alejo Carpentier, "Blacamán the Good, Vendor of Miracles".

\section{DOI: https://doi.org/10.24029/lejana.2017.10.158}

Recibido: el 31 de julio de 2017

Aceptado: el 15 de septiembre de 2017

Publicado: el 4 de noviembre de 2017 
Vi la posibilidad de establecer ciertos sincronismos posibles, [...] recurrentes, por encima del tiempo, relacionando esto con aquello, el ayer con el presente.

(Alejo Carpentier)

\section{Introducción}

En cuanto al uso del término realismo mágico, baste aludir a dos autores que detallan las confusiones y los deslices respectivos (Rodríguez Monegal, 1975: 26-27 y Bényei, 1997: 14). ${ }^{1}$ La fertilidad del término no se puede cuestionar: ni este artículo se habría escrito si su uso estuviera bien aclarado. Ambos componentes suyos presentan problemas: el "código realista" (Roas, 2001: 27) suele entremezclarse con algo entendible como el mimetismo; en cuanto a lo maravilloso - distinto del realismo mágico en su origen, pero más tarde muy unido a su ideario (Rodríguez Monegal, 1975: 27) - Carpentier declara: "lo maravilloso comienza a serlo cuando surge de una inesperada alteración de la realidad (el milagro)" (1967: 116), confundiendo términos que tal vez convendría tener separados. ${ }^{2}$ Apelando a la "función mágica del arte" (Rama, 1970: 40), se podría argumentar, además, que el término “mágico" es demasiado general para delimitar cualquier género narrativo, ya que " $[\mathrm{u}] \mathrm{n}$ orden muy diverso los rige, lúcido y ancestral. La primitiva claridad de la magia" (Borges, 2006: 177). ${ }^{3} \mathrm{Sin}$ embargo, cuanto más amplia es la discusión acerca de un término, más difícil resulta desprenderse de él (¿será esta su propia magia?). Su persistencia también se explica por su papel desempeñado en la búsqueda de identidad de Hispanoamérica (tratado por Abellán, 1972: 55-76), y, por otro lado, — visto desde otras partes del mundo — por la superficial y errónea identificación de Hispanoamérica con la zona tropical (Henríquez Ureña, 1998: 252), y de esta con el realismo mágico.

Teniendo en cuenta lo dicho, este artículo propone 1) observar algunas manifestaciones de dos exponentes (Carpentier y García Márquez) con sus inherentes contradicciones; 2) llamar la atención sobre ciertos elementos históricos, enfatizando aquellos que han podido quedar menos expuestos por su lejanía y que han podido contribuir a la dilatación del término hasta a acepciones extraliterarias; 3) ver cuáles son algunos elementos textuales que aportan a su vigencia y productividad. El ejemplo para ello será "Blacamán el bueno, vendedor de milagros", cuento del mismo García Márquez, por provenir precisamente de la región prototípica mencionada por Henríquez Ureña; y porque el cuento tematiza el elemento milagroso (y por contigüidad, lo mágico y lo maravilloso) a partir del mismo título.

A propósito de títulos: el de este estudio dice "un momento" por tres razones: porque no es su propósito reflexionar acerca de la vigencia o la actualidad del realismo mágico; porque, definiéndolo como un momento de la historia literaria $-\mathrm{y}$ no como pasado o presente-, espero que el método de las consideraciones apunte a un mecanismo más

\footnotetext{
${ }^{1}$ Bényei incluso declara que el término se ha vuelto casi inutilizable para el análisis, y es más adecuado para el periodismo (1997: 14).

${ }^{2}$ Las distinciones que hace Morales en su artículo son muy útiles para precisar y delimitar estos términos (maravilloso, milagroso, mágico y feérico); seguro que, de haberlas tenido antes, el discurso sobre el tema se habría complicado mucho menos.

${ }^{3}$ La problemática es semejante a la que señala Barrenechea en cuanto a la aplicabilidad de los "temas del Yo" y “temas del Tú" en la teoría de Todorov (2007: 67). Encontré la cita de Borges en Rodríguez Monegal (1975: 28); el número de la revista a la que se refiere está en Internet, libremente accesible: https://www.triquarterly.org/issue-viewer\#/77281 (las frases de Borges: 213-214).
} 
universal y que este eventualmente pueda replantearse a la hora de observar otros contextos literarios; por último, porque así puede referirse tanto al momento de la creación de una obra como al de su recepción.

\section{Los deslices de Carpentier; una nota sobre Márquez}

Sirve para entender mejor la naturaleza de las confusiones si echamos una mirada a las ideas de Carpentier —que, si bien utilizó solo el concepto de "lo real maravilloso", contribuyó sin duda a los fundamentos del ideario del realismo mágico-, en especial, a su artículo "De lo real maravilloso americano":

Los que no creen en santos no pueden curarse con milagros de santos, ni los que no son Quijotes pueden meterse [...] en el mundo de Amadís de Gaula [...] Prodigiosamente fidedignas resultan ciertas frases de Rutilio en Los trabajos de Persiles y Segismunda, acerca de hombres transformados en lobos, porque, en tiempos de Cervantes se creía en gentes aquejadas de manía lupina. Asimismo [...] Marco Polo admitía que ciertas aves volaran llevando elefantes entre las garras. (1967: 116-117)

Sin embargo, un poco más tarde declara:

Lo real maravilloso se encuentra a cada paso en las vidas de hombres que inscribieron fechas en la historia del continente [...] Siempre me ha parecido significativo el hecho de que, en 1780, unos cuerdos españoles [...] se lanzaron todavía a la busca de El Dorado, y que [...] el compostelano Francisco Menéndez anduviera por tierras de Patagonia buscando la ciudad encantada de los Césares (1967: 118)

Por tanto, primero afirma que el fenómeno existió en ciertos lugares y épocas, luego lo atribuye exclusivamente al continente americano y a su efecto sobre las personas en contacto con él. Hablando sobre el período del Siglo de las Luces, implícitamente excluye que haya podido persistir orgánicamente otra manera de pensar que inspirara a los exploradores, y le otorga a una época un único posible modo de ver el mundo. ${ }^{4}$

Dos notas más acerca de estas citas, sobre las cuales insistiré más adelante: 1) en ambos casos se mencionan noticias transmitidas por fuentes orales (las que describió Marco Polo en su libro de viajes, y las que motivaron a los "cuerdos españoles" a su aventura); 2) las primeras noticias de América llegaron a Europa justamente en el período delimitado por los dos ejemplos aducidos (después de Marco Polo y antes de Cervantes).

Un poco antes, en el mismo texto, hablando de lo maravilloso, Carpentier opina que surge de una "inesperada alteración de la realidad", de una "iluminación inhabitual", "singularmente favorecedora de las inadvertidas riquezas de la realidad", que resultan en "una exaltación del espíritu" (1967: 116). Parece, sin embargo, que no advierte un hecho fundamental: todas estas palabras ("inesperada", "inhabitual", "inadvertida") denotan fuertemente un sujeto ("un espíritu") al que los fenómenos se le presentan como tales, por tanto, otorga un valor absoluto a unas vivencias subjetivas, y calificando de maravillosa la

\footnotetext{
${ }^{4}$ Henríquez Ureña, en su lúcido razonamiento — en el año de la publicación del concepto "realismo mágico" por Franz Roh-, parece poner el dedo en la llaga: "En América conservamos el respeto al énfasis mientras Europa nos lo proscribió; aun hoy nos quedan tres o cuatro poetas vibrantes, como decían los románticos. ¿No representarán simple retraso en moda literaria? ¿No se atribuirá a influencia del trópico lo que es influencia de Victor Hugo?” (1998: 251).
} 
realidad americana, ${ }^{5}$ la encasilla dentro de un punto de vista marcadamente europeo (Bényei, 1997: 34). ${ }^{6}$ En resumen: el afán de encontrar la identidad hispanoamericana le impide ver la encerrona lógica de ciertas propuestas. ${ }^{7}$

Para ver otro ejemplo del mismo ensayo de Carpentier, hablando de las maravillas artificiales de Maldoror, las confronta con el carácter orgánico de lo maravilloso americano reelaborado por él artificialmente en El reino de este mundo - : "Pero en América [...] existió un Mackandal dotado de los mismos poderes por la fe de sus contemporáneos, y que alentó, con esa magia, una de las sublevaciones más dramáticas y extrañas de la historia" (1967: 119). De nuevo, Carpentier parece atribuir las características de una visión del mundo a un continente.

La confusión nace, otra vez, de identificar una visión del mundo exclusivamente con un entorno, sin considerar las posibles analogías existentes. Como si la tasa de alfabetización - en directa relación con el peso de la oralidad - fuera característica permanente e inevitable de un entorno. ${ }^{8}$ No quiero decir que no se pueda hacer asociaciones como resultado de una abstracción —es más, tal vez sean humanamente ineludibles-, pero en textos no-ficcionales, cuya finalidad no es adelantar el pensamiento sobre la identidad de un continente, se requeriría más cautela.

Por último, una acotación sobre García Márquez, que se declara "realista" en cuanto a Cien años de soledad, proclamando que en América todo podía pasar y ser real (según Irish, citado por Bényei, 1997: 37). En esta argumentación utiliza el concepto de diferencia ontológica ya mencionado, propone a la vez un eslogan altisonante, contribuye a proyectarlo al público y a perpetuar así este lugar común continental. Sus repetidas y hábiles alusiones a su propio realismo y su innegable efectividad publicitaria se entienden mejor con la ayuda de la intervención de Salvador Garmendia:

García Márquez [...] mismo lo afirmó [...] que había aprendido a narrar Cien años de soledad fijándose en la cara de palo que ponía la sirvienta de su casa cuando contaba [...] que una persona subía al cielo o que [...] se transformaban en gusanos; lo contaba con una [...]

\footnotetext{
${ }^{5}$ Dice Rodríguez Monegal sobre las ideas originales de Roh: "For him, «magic» was a way of perceiving reality, not a way of asserting the existence of any supernatural or «marvellous» dimension" (1975:26; "Para él, «lo mágico» era una manera de percibir la realidad, y no una manera de reivindicar la existencia de cualquier dimensión sobrenatural o «maravillosa»”, la traducción es la mía). En Carpentier, vemos un desliz entre estas dos categorías: ignorando su propia limitación derivada de su subjetividad — también ignorada- plantea su propia visión como característica de lo que ve. En términos sofisticados, confunde la fenomenología con la ontología, y de ahí pasa a proclamar la diferencia ontológica del mundo americano.

${ }^{6} \mathrm{Al}$ parecer, Carpentier no se dio cuenta de su propio condicionamiento, explicado también por Ángel Rama: "Es sabido que los escritores de la vanguardia hispanoamericana descubrieron su América en Europa. Aquella frase que cita Carpentier, según la cual, oyendo a Stravinsky, descubre que estas disonancias también existían allí en Regla" (1970: 47).

${ }^{7}$ Este problema se presenta una y otra vez en las apuestas ideológicas afines: "si el triunfo político de los Estados Unidos ha sido el triunfo como nación, el triunfo político de Hispanoamérica ha de ser el triunfo como continente, y, en definitiva, del hispanoamericanismo" (Abellán, 1972: 60). En estos casos, se toma como inevitable una única vía de desarrollo arbitraria, y se ignora la contingencia de elementos o procesos fuera del propio planteamiento.

${ }^{8}$ Este supuesto entorno puede ser tanto geográfico como histórico. Carpentier - a pesar de su frase citada en el epígrafe - incurre en ambos tipos de error, que nace de la falsa visión que hace corresponder a una época o a un territorio su característica más destacada o novedosa, sin admitir la posible persistencia de otras condiciones, creencias y visiones del mundo a la vez o la coexistencia de múltiples cosmovisiones.
} 
naturalidad tal, como si contara el hecho más simple y más cotidiano de la vida. (Rama, 1970: 54-55)

Por una parte, estas declaraciones satisfacen la demanda popular que tanto se nota en carteles publicitarios (“ ¡Basado en hechos reales!”), por otra parte, le afianzan su credibilidad: no se trata de su propia invención, se refiere a una autoridad ajena (su abuela, la sirvienta o quien sea). El hecho apelado como real no es más que la narración preexistente a su texto, cuya preexistencia suplanta engañosamente la necesidad de referirse a cosas veraces. $\mathrm{O}$, dicho de otra forma, en esta argumentación, la narración modelo se plasma como objeto autónomo perteneciente a la realidad. ${ }^{9}$

De acuerdo con la división ficción / no-ficción, se puede decir que Carpentier, cayendo en generalizaciones en su ensayística, comete un fallo lógico, mientras que Márquez, en su producción artística logra un acierto: "una de las formas de enriquecer la literatura que ha tenido García Márquez ha sido apelar a esta línea [de la cultura analfabeta]. Esta línea, también puede ser la línea de la literatura caballeresca del siglo XV, como señala Vargas Llosa" (Rama, 1970: 62); eso es, mientras no lo extienda a campos extraliterarios. ${ }^{10}$

\section{Componentes históricos de la hibridez: desde la Baja Edad Media hasta las vanguardias}

En el apartado anterior, ya ha surgido el nombre de Marco Polo. Sus noticias formaron parte de los fundamentos de Colón para buscar el paso hacia el Oriente, tal como lo recuerda Abellán: "Colón inicia su cuarto viaje (1502-1504) sin encontrar el paso al Índico, hasta que [...] algunos indígenas le hablaron de minas de oro, que identificó con los de Ciamba, de que habla Marco Polo" (1972: 31). La sorpresa, el continente enteramente nuevo, fue solo pura casualidad, que no encajó en sus preconceptos, y a los cuales intentó ajustar su descripción en sus cartas de viajes, pero que no anula su concepción preliminar.

Es interesante la suerte complicada del texto de Polo. En sí, muchas veces narra historias que le habían sido transmitidas por vía oral a lo largo de su viaje. Pero, más allá de esto, el manuscrito original no se ha conservado, y las versiones se iban formando mediante numerosas traducciones. ${ }^{11}$

Hay que mencionar todavía que el primer editor crítico del texto de Marco Polo fue Giovanni Battista Ramusio: publicó el resultado de su trabajo en $1558 .{ }^{12}$ El personaje cobra

\footnotetext{
${ }^{9}$ Es imposible dejar de notar cierta analogía entre esta transgresión del límite de dos órdenes distintos y el desliz de Carpentier entre fenomenología y ontología: en ambos casos se le da una autoridad total a algo que no debería tenerla.

${ }^{10}$ Resulta curioso observar hasta qué punto inciden en la mercadotecnia estos conceptos: "el relato recuerda al mismo tiempo las gestas medievales y los cantos provenzales o trovadorescos, aunque, como siempre, inmersos en ese mundo denso y frutal del Caribe americano" (García Márquez, 2004: tapa posterior), insistiendo sobre esta dualidad espaciotemporal. Se ve, por tanto - teniendo en cuenta también las entrevistas del autor- que, en estos casos, lo extraliterario se pone en juego enseguida, tanto por la propaganda comercial como por aquella ideológica.

${ }^{11}$ Camesasca menciona una variante que fue un texto italiano traducido del latín, que a su vez había sido traducido de un texto toscano, versión adaptada del veneciano, antes traducida desde el francés, al que debía de haber llegado a través de alguna traducción (2003: 14).

${ }^{12}$ Según algunos estudiosos, la recopilación es acertada, pero otros opinan que, para embellecer el resultado, añadió numerosas otras descripciones provenientes de viajeros posteriores (Camesasca, 2003: 17). Esto influye en la complejidad de las actuales ediciones críticas, y también demuestra — de modo más importante— cuántos pasos, traspasos y variaciones sufrió la historia de Marco Polo en la época entre los siglos XIV y XVI.
} 
una relevancia especial, ya que es conocido también como coleccionista de novedades de América, y por su relación estrecha con Gonzalo Fernández de Oviedo, uno de los historiadores del descubrimiento, cuya carta también se conservó en su colección. Así que él también colaboró en la primera difusión de la imagen de América del Sur en Europa (Arciniegas, 2001: 127-128). Por tanto, la formulación de la imagen del lejano Oriente y del lejano Oeste confluyó en manos de una misma persona, de dudosa credibilidad según varios expertos.

Hay que mencionar otra fuente medieval más, que pudo cimentar los conocimientos geográficos y la cosmovisión de Colón y de aquellos que supieron de sus relatos. Cinco años después de la vuelta de Marco Polo a Venecia, Dante Alighieri llegó al "mezzo del cammin di nostra vita”. Citando a Abellán:

Las ideas de Colón sobre el asunto constituyen una extraña mezcla entre cosmografía, profecía y mística.

En la carta dirigida a los Reyes Católicos, en octubre de 1498, dice Colón: «Yo no temo que el paraíso terrenal sea en forma de montaña áspera como el escribir dellos nos amuestra, salvo que sea en el colmo [...]» (1972: 24)

Es imposible no recordar aquí la Divina comedia de Dante: la descripción del último viaje de Ulises, más allá de los confines del mundo conocido (Infierno, Canto XXVI, 106142) y la montaña del Paraíso terrenal (versos 133-135), el último panorama que se abrió ante el aqueo y sus compañeros (Dante, 2003: 185-186). Es absolutamente útil tener en cuenta las fuentes concretas de Colón, y constatar la influencia y la persistencia de semejantes cosmovisiones durante varios siglos más, tal como puede sugerirlo la cita de Carpentier al inicio de este artículo.

Volviendo a la actividad de Ramusio, su figura nos lleva al segundo momento de la formación de la imagen de América: después de los preconceptos, llegó el período de los primeros relatos de viaje. Lejos de pretender un repaso exhaustivo, cito nada más algunos elementos que apuntan a las fuentes del ideario de los viajeros: Bernal Díaz del Castillo comparó uno de los lugares hallados a los que se narraban en el libro de Amadís; Cristóbal de Olid nombró la península de California para recordar un topónimo que aparecía en Las sergas de Esplandián (Arciniegas, 2001: 102); Venezuela recibió su nombre por la semejanza con la ciudad de Venecia, para no mencionar el río Amazonas y la leyenda de las guerreras de una teta.

$\mathrm{Y}$, con esto, ya incurrimos en la naturaleza de cualquier relato, que se agudiza si se habla de territorios desconocidos: hay que decir cosas que el público pueda asociar a sus conocimientos previos, y ubicarlas en su horizonte intelectual de expectativas. Si a eso le añadimos la voluntad de justificarse y el consiguiente refuerzo de los preconceptos, o la tendencia a jactarse de las propias aventuras engrandeciéndolas, tenemos un conjunto de rasgos que pudieron caracterizar las informaciones que se difundieron en Europa - en un proceso supuestamente semejante a lo visto en cuanto a García Márquez-, contribuyendo al rápido e inamovible asentamiento de la representación de América en la imaginería popular. ${ }^{13}$

\footnotetext{
${ }^{13} \mathrm{El}$ valor de las primeras noticias y la fijación de su contenido se puede apreciar ciertamente en nuestra época, cuando el bombardeo mediático de las noticias privilegia la primera aparición de un tema y apenas deja lugar a la profundización o a la rectificación posterior.
} 
Tal vez, la calidad maravillosa de América puede considerarse efectivamente como el relicto de la imaginería medieval. No en vano apunta Henríquez Ureña:

En la literatura, nuestra interpretación del indígena ha sido irregular y caprichosa. Poco hemos agregado a aquella fuerte visión de los conquistadores como Hernán Cortés, Ercilla, Cieza de León, y de los misioneros como fray Bartolomé de las Casas. Ellos acertaron a definir dos topos ejemplares, que Europa acogió e incorporó a su repertorio de figuras humanas: el «indio hábil y discreto» [...] y el «salvaje virtuoso» [...], personaje que tanto sirvió a los pensadores europeos para crear la imagen del hipotético hombre del «estado de naturaleza» anterior al contrato social. (1998: 280)

Puede resultar provechoso recordar concisamente el descubrimiento de los actuales territorios de los Estados Unidos, para evocar las primeras causas de las diferencias entre la percepción que se tenía de las dos partes del continente — si se quiere, el contrapeso del Sur, o la falta de lo maravilloso en el Norte-

La colonización del norte [comenzó] solamente [...] en el año 1620 [...] La colonización completa de las nuevas tierras es [...] muy tardía [...] hasta el punto de que sólo en 1848 se produce la adhesión de los últimos territorios [...] (Abellán, 1972: 41-42)

Entre la colonización de los descendientes [de los primeros colonizadores de origen inglés], que para penetrar 200 kilómetros tierra adentro habían necesitado dos siglos, y la colonización ibérica, que en treinta años recorre 24 millones de kilómetros, hay una diferencia que responde a dos formas radicalmente diferentes de entender la vida y el mundo. (1972: 44-45)

Preconceptos opuestos, objetivos antitéticos en los viajeros, épocas distintas, idas y vueltas según sistemas diferentes, otro tipo de noticias que llegan y otro tipo de recepción que obtienen por el horizonte de expectativas tan distante en tiempo y mentalidad. ${ }^{14}$

Dando un salto enorme en los siglos, tenemos que mencionar todavía las vanguardias. Sin aspirar a dar un panorama general - ya que la inspiración vanguardista en la novelística latinoamericana en la época de Carpentier y de Márquez es un tema ampliamente tratadome restrinjo a un resumen de algunas ideas clave pertinentes:

$[\ldots]$ los grandes transformadores de la literatura hispanoamericana $[\ldots]$ reciben una lección enteramente nueva, incipiente, discutida, minoritaria en Europa, pero cuya importancia es inmensa en la historia de la cultura, que es el surrealismo. Sin el surrealismo no existiría el arte moderno" (Rama, 1970: 48)

Although in his criticism [of Ortega] Borges never made any reference to surrealism, it is obvious that in his rejection of realistic literature, Borges was closer to what Breton has said in the First Manifesto (1924) than to any theoretician of the time. ${ }^{15}$ (Rodríguez Monegal, 1975, 31)

Se sabe, además, que Carpentier acaba rechazando las propuestas de Breton y del surrealismo, tachándolas de artificiales (1967: 115), pero no puede hacer menos de utilizarlo en sus técnicas de escritura, o al menos de manera pasiva, acusando el cambio en el horizonte de expectativas de los lectores producido por el propio surrealismo. Hablando sobre Asturias,

\footnotetext{
${ }^{14}$ La afirmación se mantiene irreprochable, tal vez, hasta la Fiebre del Oro de California y el sueño estadounidense, pero la comparación de estas con la búsqueda de El Dorado correspondería a otros estudios.

15 "Aunque Borges, en sus críticas [hacia Ortega], nunca hizo referencia alguna al surrealismo, es obvio que, en su rechazo de la literatura realística, Borges estuvo más cerca a lo que dijo Breton en su Primer Manifiesto (1924) que cualquier otro teórico de la época” (la traducción es la mía).
} 
Bényei también resalta la mezcla de la visión mítica del mundo y de las influencias del surrealismo (1997: 37). Es fácil suponer, por tanto, que sin las vanguardias no habría sido posible abrir el camino de vuelta a lo mítico, ni revitalizar los elementos antiguos de la imaginería sobre América.

\section{Dualidad en el horizonte de expectativas}

En los dos capítulos anteriores se han visto los distintos horizontes fundamentales para el tema del ensayo. Al primer momento le corresponde la reducción y la asimilación de lo nuevo a sus conocimientos previos, la identificación y el consiguiente encasillamiento del nuevo ente, al cual van a adherirse las figuraciones posteriores para quedar reconocibles. En semejante sentido acuñó O'Gorman el término “invención” de América, para sustituir el del “descubrimiento" (Abellán, 1972: 38-39).

La investigación sobre la literatura fantástica — dado que su tema se revuelve en torno al choque de los elementos conocidos y desconocidos — ha prestado atención destacada a este aspecto, con la mira puesta en introducir un criterio de análisis más fiable que las impresiones del lector, buscando huellas textuales (Barrenechea, 2007: 59). Ángel Flores intentó definir el realismo mágico como mezcla de lo real y lo fantástico (Bényei: 1997: 30), pero es que ni la mezcla, ni las distinciones son satisfactorias del todo. Morales menciona el "mundo conocido" (2007: 245) — ¿por quién?, se debe preguntar con vistas a la omisión citada de Carpentier-, y Roas también comenta el criterio de contrastar o no los hechos con "nuestra experiencia del mundo" (2001: 15). Para él, el límite de lo fantástico es evidente: si la confrontación se vuelve necesaria, el texto entra en esta categoría, y si no, queda fuera, por ejemplo, en el territorio de lo maravilloso. ${ }^{16}$

De hecho, parece que el realismo mágico no problematiza la frontera entre los dos, sino que solo utiliza elementos de ambos. Es decir, en el mundo intradiegético, porque el choque de los elementos inesperados puede resultar muy atractivo al lector; pero para ello harían falta experimentos de lectura basados en las ciencias cognitivas, para no acabar en la vaguedad. Sin embargo, esta certeza también se ve cuestionada si consideramos una característica de lo neofantástico: la falta de problematización por parte de los personajes del mundo narrado. ${ }^{17}$

Es fundamental la existencia de varios horizontes de expectativas -intra- o extradiegéticos - : una, que no cuestiona los elementos sobrenaturales, inexplicables o contradictorios con las reglas de la realidad, y otra, que sí tiende a hacerlo. En este sentido cita Bényei a Floyd Merrell y a Gerald Martin, quienes hablan de una dialéctica (1997: 3940), pero cabe sopesar bien si hay una dialéctica o una lucha intratextual para unificar las dos,

\footnotetext{
${ }^{16}$ Transponiendo este criterio a nuestra temática, sería intrigante saber del horizonte de expectativas que tenían los indígenas transportados a Europa como muestras. ¿Verían los elementos de este mundo nuevo para ellos como algo milagroso? ¿Al ver funcionar una rueda por primera vez? ¿Qué decir de las impresiones de los indígenas que veían llegar a los conquistadores en sus caballos, seres desconocidos, en cumplimiento de sus profecías? Anoto estas interrogantes para señalar que no somos capaces de ver nuestras propias circunstancias como maravillosas, por estar acostumbrados, y para volver a cuestionar lo maravilloso como algo exclusivo de lo americano.

${ }^{17}$ Para un análisis más profundo, consúltese el artículo de la profesora Orosz en el presente número de esta revista.
} 
o se trata solo de la reacción del lector distintamente acostumbrado, y el texto, en cambio, solo disfruta la convivencia de las dos en esta hibridez.

\section{Los dos Blacamanes}

Siguiendo los fenómenos arriba descritos en términos históricos (visión del mundo mítica / medieval / religiosa; inspiración vanguardista), veamos ahora sus huellas perceptibles en el texto de Márquez. La definición de lo mágico dada por Morales restringe provechosamente su campo semántico, y excluye una parte de los elementos maravillosos: "gran parte de los sucesos [...] que [...] se relacionan con lo mágico se cobijan bajo una noción del mal [...] presentes en buena parte de la literatura de terror" (2007: 252). Pero el cuento "Blacamán el bueno, vendedor de milagros" entra también en este territorio reducido, debido a la presencia del mago malvado, de la "mujer tan tierna que podía pasar suspirando a través de las paredes, [...] recuerdo inventado [...] artificio [...] para burlar a la muerte con lástimas de amor" (2004: 87), del "baúl de tamaño premonitorio", del "sepulcro blindado" y de su "horror" (2004: 91).

Hablando de la convivencia híbrida de dos órdenes distintas, conviene citar a Rama: “[García Márquez,] en vez de colocar uno al lado de otro, lo real y lo fantástico; en vez de elegir puramente lo fantástico; en vez de permitir el pasaje de las dos zonas distinguiéndolas, las une y decreta la realidad de lo fantástico. Y lo decreta con resolución. Efectivamente Remedios la Bella asciende al cielo" (1970: 52). El ejemplo es llamativo, porque recuerda vivamente la Asunción de la Virgen. Asimismo, en "Blacamán el bueno" aparecen o incluso abundan los elementos que recuerdan motivos religiosos, indisociables de las supersticiones populares: la primera resurrección milagrosa (2004: 82), el posterior rechazo irónico de resucitar a los muertos para no airarlos (2004: 89) y la inversión final del motivo, convirtiéndolo en método de tortura infinita (2004: 92); la ubicación del inicio en el domingo de ramos (2004: 82), y la evocación del miércoles de ceniza (2004: 90); "la mano de Dios en un frasco" (2004: 83); la voluntad de obtener mejoría o conjurar la propia mala suerte con sacrificios expiatorios: "me dijo que [...] ahora conocía la verdad, y era que yo le había vuelto a torcer la suerte, de modo que [...] lo mismo que me la torciste me la vas a enderezar" (2004: 87) -recuérdense las numerosas ofrendas en el Antiguo Testamento (Gn 4, 3-8; Gn 22, 114) - ; la división de los enfermos — "los lazarinos a la izquierda, los epilépticos a la derecha" (2004: 89) - evoca la parábola del Juicio Final (Mt 25, 31-33); las amenazas de los sabios con "el infierno de Simón el Mago" y su incitación a "que llegara a ser santo" (2004: 90).

A pesar de la presencia del narrador intradiegético, los elementos milagrosos aparecen fuertemente ligados a la percepción de la multitud, inicialmente por la primera persona del plural, que todavía incluye al narrador — “todos creímos que se la iba a comer" (2004: 81); "Todo el mundo lo daba por muerto", "como todos lo habíamos visto con nuestros propios ojos" (2004: 83)—; luego, a través de su separación gradual de la multitud — "Por supuesto que se amontonaron", "solo quedábamos en el puerto los más perplejos" (2004: 83) —; hasta la inversión de su posición, cuando está frente a multitudes -“me perseguía un séquito de sabios" (2004: 90), cuando ya se dirige a la muchedumbre desde su posición privilegiada las repetidas frases: "damas y caballeros" (2004: 89) y "señoras y señores" (2004: 81, 85, 
91)—. ${ }^{18}$ Esta situación de la compraventa pueblerina es un escenario típico asociado con la aceptación de las maravillas del mundo por las creencias y supersticiones populares. ${ }^{19}$

Estas escenas presentan una serie de milagros públicos, acogidos por la multitud, de nuevo, con numerosas analogías en la Biblia — baste citar, por ejemplo, la serpiente de bronce (Nm 21, 4-9) o las multiplicaciones de los panes (2 Re 4, 42-44; Mt 14, 13-20)—, en contraste con otro tipo, el de los milagros privados, que se revelan ante una sola persona, y pueden inducir un cambio radical en la suerte de esta persona -así sucede con Moisés en el episodio de la zarza ardiente (Ex 3, 1-22), y con Blacamán:

$[\ldots]$ y entonces fue cuando sucedió, como en un sueño, que el conejo no solo resucitó con un chillido de espanto, sino que regresó a mis manos caminando por el aire.

Así fue como empezó mi vida grande. $(2004: 88-89)^{20}$

Tal vez sea este último tipo el más interesante, porque en su caso no hay posibilidad de atribuirlo a la percepción mediada por la focalización del pueblo supersticioso. Evidentemente, en este sentido, el ejemplo del cuento difiere también del ejemplo bíblico, ya que aquí opera un narrador intradiegético y homodiegético. Este hecho es importante porque deposita la decisión de confiar en él o menos en las manos del lector. Y, por tanto, ejemplifica la encrucijada donde los dos horizontes de expectativas se separan en la interpretación de lo leído.

Aunque no suponga un problema para una visión mítica, el manejo del tiempo de la historia es otro aspecto donde la lectura desde una cosmovisión moderna percibe una escisión entre relato y realidad, manifestándose en una mezcla de intervalos sobrehumanos e incertidumbre, repetición cíclica — reforzado con la repetición de ciertos giros- con contados eventos irrepetibles:

[...] pues de eso hace más de un siglo y ambos nos acordamos todavía como si hubiera sido el domingo pasado. (2004: 83)

[...] vamos a ver si se atreve a preguntarle cuándo va a morir, pero yo nunca conseguí adivinar ni la fecha en que estábamos (2004: 85)

No sé cuánto tiempo había pasado (2004: 88)

Alguien que parecía muy impresionado [...] consiguió nadie supo dónde y le llevó dentro de un frasco [...] (2004: 81); Alguien que quizá no olvidaba [...] consiguió nadie supo dónde y le llevó dentro de una lata [...] (2004: 91)

[...] él la destapó con tantas ganas que todos creímos que se la iba a comer [...] (2004: 81)

\footnotetext{
${ }^{18}$ Esta última frase sufre una transformación reveladora: primero, el narrador lo escucha junto con el pueblo, luego aparece en el discurso con los dos Blacamanes juntos, después vuelve cuando el bueno ya ha derrotado al malo y están separados, y, por último, parece que la invocación se dirige a los lectores, que se funden de esta forma con el público intradiegético.

${ }^{19}$ Un ejemplo análogo del mundo de la ópera: la cavatina del doctor Dulcamara en L'elisir d'amore de Donizetti: el doctor se presenta ante una multitud en el pueblo y se pone a anunciar y a vender sus pociones milagrosas. El embustero no se descubre como tal para todos los personajes: Nemorino se cree que su felicidad se debe al elixir (vino de Burdeos) del doctor. La ópera es un evidente ejemplo -seguramente se podrían citar muchos más- de esta ubicación como una vieja situación tipo de obras ficcionales.

${ }^{20}$ Los parangones bíblicos están presentes también en otras obras de García Márquez, no cabe recordar más que en la genealogía Cien años de soledad, a la que Bényei dedica un apartado en especial (1997: 112-125), y la famosa lluvia es también evidentemente asociable al diluvio universal.
} 
[...] él las destapó con tantas ganas como si de verdad se las fuera a comer [...] (2004: 91)

Fue ésa la única vez [...] que me fracasó la ciencia (2004: 91)

[...] si acaso se ha vuelto a morir lo vuelvo a resucitar, pues la gracia del escarmiento es que siga viviendo en la sepultura mientras yo esté vivo, es decir, para siempre. (2004: 91)

Por otro lado, están presentes algunos elementos del mundo real, que — volviendo a citar la portada posterior - inmergen el texto "en ese mundo denso y frutal del Caribe americano", por tanto, contrarrestan las "irrealidades", sobre todo en lecturas que conocen con más detalle el entorno sociopolítico y geográfico de las obras: aparecen "los gringos", los militares — "el comandante del acorazado" (2004: 86), "el barítono de la ópera de los piratas de Nueva Orleans" y "la vida de ministro" (2004: 90), se nombra Santa María del Darién (2004: 81, 91), soplan "los vientos eternos de la Guajira" (2004: 86), se mencionan "los virreyes" (2004: 84) "las ruinas de una misión colonial" (2004: 87), se habla de "la electricidad" y la "máquina de coser" (2004: 85-86)—.

Hay un hueco entre los dos extremos que, como se ha visto, el texto no procura llenar ni explicar, sino deja paso a la asociación y a la sugestión. Recuérdese la cita de Borges y considérese otra más: “[...] la magia es la coronación o pesadilla de lo causal, no su contradicción [...] Para el supersticioso, hay una necesaria conexión no sólo entre un balazo y un muerto, sino entre una muerta y una maltratada efigie de cera o la rotura profética de un espejo o la sal que se vuelca o trece comensales terribles (2006: 178)".

Es este mecanismo de lectura - cercano al pandeterminismo intraficcional enfatizado por Todorov en cuanto a la literatura fantástica (2002: 94-107)—, esta característica mágica de la literatura que el texto de García Márquez permite ponerse en marcha concienzudamente, dejando de lado el cuestionamiento por parte de sus personajes, así como las explicaciones - para que intente llenar los vacíos del entendimiento, y es este proceso que hace que todo eso resulte tan atractivo. Y, en líneas generales, este es el mismo proceso, relegado aquí al espacio relativamente más seguro y —en cierto sentido - lúdico del texto ficcional, que se desencadena en el ser humano frente a acontecimientos no literarios y a nuevas realidades, tal como sucedió con los viajeros pioneros antes mencionados. Es decir, en los textos de esta índole de García Márquez, gracias a la intervención liberadora del surrealismo y otras vanguardias, se reencuentra y se reactiva un modo de ver que se creía ancestral u obsoleto, que más que eso, podría revelarse como una facultad general de la mente humana.

\section{A modo de conclusión}

Si se observa con cuidado, se verá que el acercamiento al "realismo mágico" ha sido más bien psicológico en Roh, porque se enfocaba en la percepción de lo que se ve, y en su reelaboración interior que se hace de ello, lo cual afectará también nuestras reacciones ante los hechos. En un análisis de crítica literaria, esto tiene que reflejarse en la atención prestada a las características textuales del narrador y de los personajes. Por otro lado, la reelaboración interior es un paso necesariamente anterior a la narración de lo que hayamos experimentado / vivido / escuchado — nótese la multiplicidad de los filtros en el último caso-, y esto se 
observa en la investigación literaria en el acto mismo de narrar, en el narrador principal y en los narradores internos en la historia.

Insistiendo en la importancia de los dos principales horizontes de expectativas, y refiriéndonos al más arcaico, es oportuno citar a Rama: "Porque los fantasmas tienen una realidad, la realidad que significa su acción sobre la conciencia de los hombres, la realidad que significa su constante ejercerse en el mundo de la vida interior, en el mundo de las sensaciones" (1970: 41). Este razonamiento deconstruye lo que el término "realismo" (o mimetismo) establece como su propio horizonte, porque lo remite al enfoque de los sujetos individuales, convirtiéndolo en una categoría muy diferente, sin embargo, no libre, ni arbitraria, porque — a pesar de la variabilidad cultural — se atiene a las propiedades y formas de la mente humana, pero sí más variable, difícilmente equiparable entre todos los miembros de un público lector. Un tipo de las realidades correspondientes puede coincidir con los preceptos que generalmente se entienden bajo el concepto de "realismo mágico", o, mejor dicho, con los que aparecen como la visión de los personajes en los textos pertinentes. Pero si el horizonte del lector no coincide con este tipo, puede ser justamente el choque lo que resulte intrigante y lo incite a la lectura.

En el caso del exotismo de América visto desde un punto de vista europeo, es justamente esta diferencia que le proporciona interés; hecho que incluso se denuncia algunas veces como reducción de Latinoamérica a un producto de exportación y a kitsch (Volek, citado por Bényei, 1997: 34). Al contrario, desde una lectura americana o americanista, el reconocimiento de los elementos propios, vernáculos puede conllevar el reconocimiento - no menos atractivo- de la propia identidad. ${ }^{21}$

La formación de esta dualidad es, sin duda, una operación esmerada por parte del escritor, ${ }^{22}$ que disemina elementos en esta hibridez, con resonancias distintas en latitudes distantes, o en estos horizontes de expectativas diferentes, y serán otros los elementos que parecerán novedosos en cada uno de ellos. La mezcla de lo novedoso — potenciado indudablemente por los influjos del surrealismo- y de lo reconocible se presenta en una mezcla idónea, y este carácter contradictorio textualiza las posibles imágenes contradictorias que se tienen sobre América. Siempre las imágenes, y no la realidad objetiva: unas imágenes que se han venido formando desde $-\mathrm{o}$ incluso antes de- las primeras descripciones. Y si hemos dicho que la repetición del término "realismo mágico" no hace otra cosa que multiplicarse y fortalecerse con cada mención, lo mismo pasará en cada lectura con la imagen de América que se transmita en estos textos.

\footnotetext{
${ }^{21}$ En este sentido hemos visto los elementos que remiten a la realidad de la región. Ha quedado fuera del enfoque de esta investigación, pero "Blacamán el bueno" también resulta susceptible de una lectura de este tipo, tal como lo sugiere la consonancia de la división Blacamán el bueno / Blacamán el malo en el cuento, y la de “América buena" y “América mala”, citada por Henríquez Ureña (1998: 252).

${ }^{22}$ Por tanto, resulta sólida y acertada la elección de Bényei a la hora de tratar el realismo mágico como modalidad de escritura, aún si no es capaz de deshacer la multiplicidad muchas veces confusa del uso del término.
} 


\section{Bibliografía}

ABELLÁN, José Luis (1972): La idea de América. Origen y evolución. Madrid, Ediciones Istmo.

ARCINIEGAS, Germán (2001): Eldorádó délibábja. Trad. László Scholz, Éva Cserháti y György Hargitai. Budapest, Nagyvilág Kiadó.

BARRENECHEA, Ana María (2007): "Ensayo de una tipología de la literatura fantástica (A propósito de la literatura hispanoamericana)". Teorías hispanoamericanas de la literatura fantástica. Ed. José Miguel Sardiñas Fernández. La Habana, Fondo Editorial Casa de las Américas: 59-69. DOI: https://doi.org/10.5195/reviberoamer.1972.2727

BÉNYEI Tamás (1997): Apokrif iratok. Debrecen, Kossuth Egyetemi Kiadó.

BORGES, Jorge Luis (2006): “El arte narrativo y la magia". Revista Sur (1932): 173-180. Recogido en la Biblioteca Virtual Universal: http://biblioteca.org.ar/libros/132517.pdf (última consulta: 06/09/2017).

CAMESASCA, Ettore (2003): "Nota”. Marco Polo: Il Milione. Milano, BUR: 5-23.

CARPENTIER, Alejo (1967): "De lo real maravilloso americano". Tientos y diferencias. Montevideo, Arca: 102-120.

DANTE, Alighieri (2001): Divina Commedia. Comentarios de Giovanni Fallani y Silvio Zennaro. Roma, Newton \& Compton.

GARCÍA MÁRQUEZ (2004): "Blacamán el bueno, vendedor de milagros". La increíble y triste historia de la cándida Eréndira y de su abuela desalmada. Barcelona, Debolsillo: 7992.

HENRÍQUEZ UREÑA, Pedro (1998): Ensayos. Madrid, Allca XX.

MORALES, Ana María (2007): "Las fronteras de lo fantástico". Teorías hispanoamericanas de la literatura fantástica. Ed. José Miguel Sardiñas Fernández. La Habana, Fondo Editorial Casa de las Américas: 241-254.

RAMA, Ángel (1970): "Fantasmas, delirios y alucinaciones". Actual narrativa latinoamericana. La Habana, Centro de Investigaciones Literarias Casa de las Américas: 3769.

ROAS, David (2001): "La amenaza de lo fantástico". Teorías de lo fantástico. Ed. David Roas. Madrid, Arco/Libros: 7-44.

RODRÍGUEZ MONEGAL, Emir (1975): "Surrealism, Magical Realism, Magical Fiction: A Study in Confusion”. Surrealismo / Surrealismos - Latinoamérica y España. Eds. Peter G. Earle, Germán Gullón. Philadelphia, University of Pennsylvania: 25-32.

TODOROV, Tzvetan (2002): Bevezetés a fantasztikus irodalomba. Trad. Gábor Gelléri. Budapest, Napvilág Kiadó. 


\section{(C) Ádám András Kürthy}

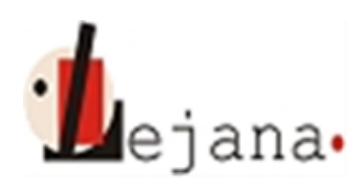

http://ojs.elte.hu/index.php/lejana

Universidad Eötvös Loránd, Departamento de Español, 1088 Budapest, Múzeum krt. 4/C 